\title{
Recent experiences of helicopter main rotor blade damage
}

\author{
Simone Weber \\ Technology Integration Manager ${ }^{1} /$ Research Student $^{2}$ \\ ${ }^{1}$ Airbus Helicopters UK, 128 Langford Ln, Kidlington OX5 AQZ, \\ ${ }^{2}$ Cranfield University UK, College Road, Bedfordshire, MK43 OAL, \\ s.weber@cranfield.ac.uk, +44 12347501115749 \\ Mudassir Lone \\ Senior Lecturer, \\ Cranfield University UK, College Road, Bedfordshire, MK43 OAL, \\ m.m.lone@cranfield.ac.uk, +441234 7501115337 \\ Alastair Cooke \\ Senior Lecturer, \\ Cranfield University UK, College Road, Bedfordshire, MK43 OAL, \\ a.cooke@cranfield.ac.uk, +44 12347501115307
}

\begin{abstract}
Results of a survey investigating commonly occurring minor rotor blade damage incidents are presented in this paper. Over 100 participants worldwide ranging from test pilots to commercial pilots and licensed engineers answered the survey. The focus of this work was to provide a user orientated context that can inform the decision making process for integrating state-of-the-art instrumentation systems for rotor blade health monitoring onboard operational helicopters. This paper highlights the dichotomy faced by designers who have a choice to either follow a reactive strategy based on operational experience or a preventative approach based on technological trends.
\end{abstract}




\section{Introduction}

It is well understood in the rotorcraft community that metallic blades in comparison to composite blades are more prone to damage [1-8]. At the same time, the engineering community is putting significant effort towards developing health monitoring systems [9-12]. The aim of this work was to provide a user orientated context that can inform the decision making process for integrating state-of-the-art instrumentation system for rotor blade health monitoring [13] onboard operational helicopters. This was done by conducting a survey with over 100 participants worldwide consisting of pilots, flight test engineers, and licensed engineers. Usually major accidents are recorded and analysed by the aviation authorities and in some cases lead to changes in regulations to increase safety. Yet, an accumulation of small damages can lead to a catastrophic event and it is important to be aware of these common minor incidents. To the authors' knowledge, there are no publicly available collections of statistical data summarising minor rotor blade damage incidents. In this paper, the authors present the reader with a short summary of statistical data collection reported in the past before providing details of the subjects who participated in this activity. The next section discusses damage occurrence rates and types. This is followed by two sections that focus on the key damage types associated with operational experience and the overall impact.

\section{Statistics}

Over the past 40 years statistics collected show that the accident rate involving helicopters has decreased drastically. In the USA alone, the rate reduced from $30.5 \%$ per 100,000 flight hours in 1970 [14] to $11.3 \%$ in 1979 [14] and decreased further to $3.19 \%$ in 2016 [15]. This reflects the huge technological advances in helicopter design and operations, such as through the availability of improved materials, more reliable power plants, advanced avionics and flight control systems. Yet, many factors can lead to an accident and these are not only dependent on factors such as pilot experience, operational environment, or weather conditions [14], but also on the helicopter as an engineered system. Out of all helicopter components the main rotor system is the most flight critical. Several fatalities are reported in the literature involving rotor blades that utilise a combination of metallic and composite materials. These were mainly due to fatigue fracture [1-7] or corrosion [8] of the metallic part. No fatal accident was reported 
that involved fatigue damage of composite materials. It should be noted that modern composite blades are qualified to EASA/FAA regulations that require the demonstration of robust manufacturing and inspection processes [16]. In addition, both fatigue safe life and damage tolerance and in-service damage limits have to be demonstrated [16]. The high fatal accident rate of metallic blades compared to composite blades suggest the need for an instrumentation systems that can detect internal damage at an early stage, highly relevant to accidents such as that discussed in Ref. [7].

Statistics presented in past studies $[17,18]$ show that the number of main rotor blade failures is relatively small compared to all other rotorcraft components. In this paper the authors make a distinction between "accidents" and "incidents" and focus on the latter. An incident is referred to as an event or occurrence, whereas an accident is an incident resulting in fatalities or injuries. Incidents involving main rotor blades are not always reported and consequently it is not known what damage commonly occurs in flight. Minor incidents involving blade defects, such as trim tab or blade protection tape damage are usually recorded internally by the maintenance organisation and tend to be treated as proprietary information. Only a few reports list events involving rotor blade damage, resulting from bird strike [19], wire strike [20], or lightning strike [21].

\section{Survey results}

In total 115 participants worldwide consisting of test pilots (30\%), flight test engineers (14\%), military pilots $(5 \%)$, commercial pilots $(36 \%)$, private pilots $(4 \%)$ and licensed engineers $(11 \%)$ answered the survey. Figure 1 show the distribution of the participants and their respective experience in terms of flight hours. Each target group provides valuable input based on their extensive flying experience, different operational tasks, maintenance expertise, and their ability to evaluate the helicopter's performance and behaviour in a practical way. The participants cover a large variety of helicopters, ranging from a maximum take off weight (MTOW) of $600 \mathrm{~kg}$ up to $18,000 \mathrm{~kg}$. Some of these pilots have flown over 100 different types of helicopters. 


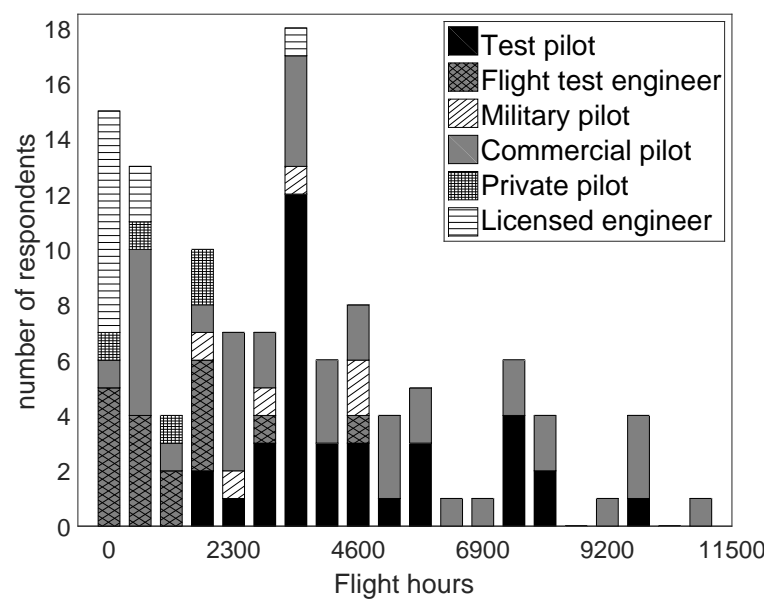

Fig. 1 Respondents flying experience.

\section{Frequency of occurrence}

Estimating how often rotor blade damage occurs is very difficult, because it depends heavily on the helicopter type, its operational environment, mission, and its handling by the pilot or maintenance engineers. For example, certain helicopters are known to be prone to water ingress through the pitch control cuff requiring rebalancing before flight. One pilot stated that on some occasions the lateral oscillations caused by water ingress were so high that the mission had to be aborted. Problems associated with water ingress or moisture absorption are strongly related to the operating environment and often occur in tropical and humid regions. Foreign Object Debris (FOD) or other erosion damage is dependent on the flying environment, such as high levels of airborne particles (sand and salt) or flying in the low-level environment (below 500 above ground level (AGL)). One pilot mentioned that when operating in the desert, erosion would happen on a daily basis but it was difficult to estimate how long it would take before the blade became unserviceable. Frequency of damage also depends on the type of mission flown. It was suggested by one respondent that damage occurs once in 500 operating hours for inland operations and once in 1000 operating hours for offshore operations and confirmed by another who stated that offshore operations are low risk missions, whereas Helicopter Emergency Medical Service (HEMS) are medium risk. High risk missions were found to be logging or agriculture (dusting/spraying) operations, or missions in a forest or jungle. It was also mentioned that in the cattle mustering industry in Australia a couple of FOD incidents occur within a month. Operating out of unprepared airfields is also more likely to cause blade damage 
than maritime operations. Apart from the already mentioned factors, rotor blade damage also depends on the pilots and maintenance engineers skills and the degree of care taken when performing ground handling tasks or using blade folding equipment. The thoroughness of periodic inspections such as the commonly used tapping test* is also critical. Tapping tests require practice and experience to be effective for identifying damages such as delamination and bond separation. Depending on the maintenance environment, damage can be easily overlooked. It was mentioned that it is very difficult to detect minor/superficial main rotor damage (especially on the upper surface) in a military environment because pilots and maintainers do not have access to work stands to inspect the full length of the blade.

\section{Experience of main rotor blade damage}

Before questioning the participants on experienced rotor blade damage scenarios, they were asked to state whether they have ever flown a helicopter with a damaged rotor blade and whether they were aware of the damage in flight. Out of all respondents, $65 \%$ had flown a helicopter with a damaged blade. In total 105 damage situations were reported and these were classified into five categories: structural damage (39\%), auxiliary components (10\%), object strike (24\%), environment (22\%), and maintenance/ground handling $(6 \%)$. A detailed breakdown of these damage types is presented in Fig. 2. It should be noted that not all damage events were noticed by the pilot or crew. Altogether $33 \%$ of the participants were not aware of the damage during flight. This feedback confirms that minor defects do not change the blade rotational frequencies significantly due to the high centrifugal loading [10] and hence, is not noticeable by the pilot or crew. Interestingly all leading edge damage or droop shroud damage went unnoticed in flight. It can be seen that the most common damage events (14 out of 105) are caused by debonding or complete loss of the blade protection tape. FOD was reported 13 times, internal damage 12 times and water ingress 10 times, followed by bird strikes and erosion which both occurred 7 times. The survey results showed that 9 out of the 12 reported internal damage occurred on composite rotor blades and in only one case the

\footnotetext{
*Some other early blade internal inspection (BIM) methods have been implemented in some Sikorsky
} helicopters blades. This method involved pressurizing the rotor blade during the manufacturing process which was connected to an indicator at the blade root changing colour if pressure was lost due to internal damage [22]. Later this indication was linked to the cockpit display. 
pilot was aware of damage. It is interesting to note that external causes are considerably greater than those due to cracks and internal damage, which account for only $13 \%$ of all listed damage events.

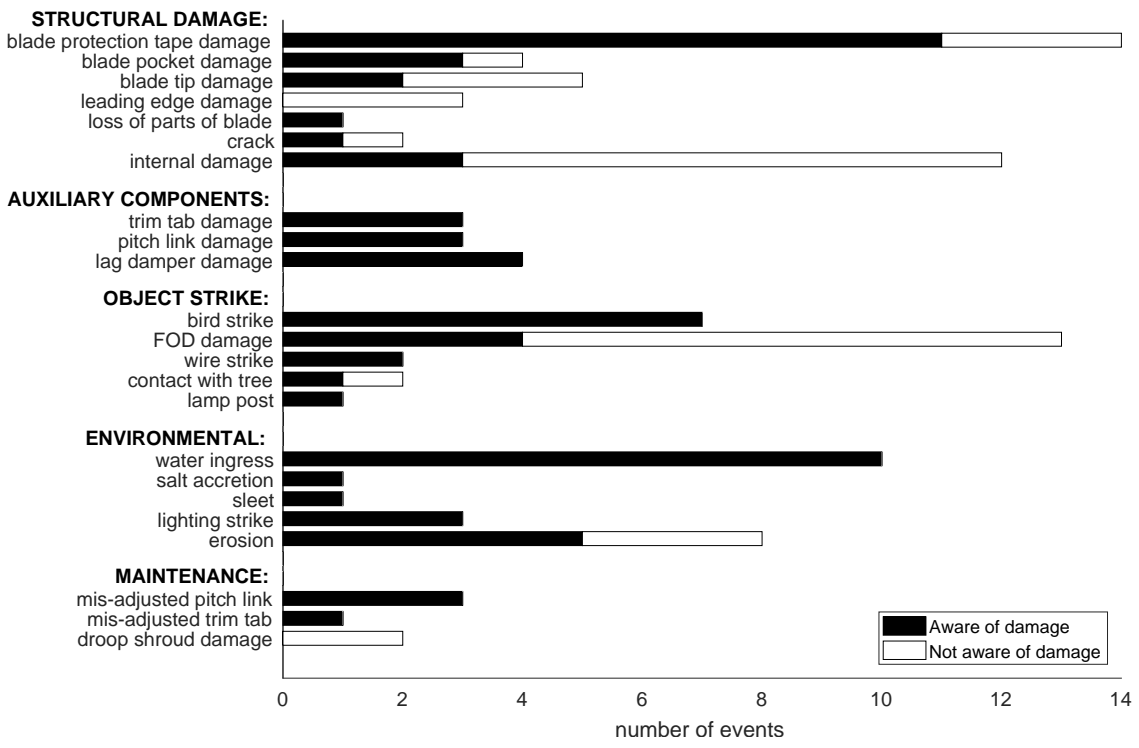

Fig. 2 Awareness of damage during flight for all occurrences.

\section{Influence of damage on helicopter behaviour and pilot workload}

This survey has found that the most common damage type is loss or damage to the blade protection tape. Three examples were given where the protection tape was damaged or separated due to heavy rain. Depending on damage severity issues such as increased or excessive vibrations accompanied by noise ("distracting whooshing sound") can occur. One pilot described that while flying through a storm cloud he/she was more concerned about the consequences of the severe weather, and only noticed the effect of protection tape loss afterwards. Tape separation can result in excessive vibrations forcing the pilot to immediately land due to unreadable instrument panel gauges. Other scenarios where parts separated from the actual structure are related to blade pocket damage. Here pilots noticed that the delaminated blade pockets "flew off in flight" resulting in increased vibration and flapping noise levels, resulting in a precautionary landing. In another case, the blade upper pocket peeled back causing very strong $1 \mathrm{R}^{\dagger}$ vibrations that resulted in dramatic increase in workload and an emergency landing.

The diverse range of helicopter missions and the vehicle's ability to land in very tight spaces also

${ }^{\dagger}$ Frequency that is an integer multiple of the rotational frequency, such as $1 \mathrm{R}, 2 \mathrm{R}, 3 \mathrm{R}$, etc. 
subject the blade tips to harsh environments. However, in most blade tip damage events, no change in behaviour was observed although some severe cases increased vibrations or increased pilot workload. One pilot reported that after a tip strike, increased vibrations were present yet there was no noticeable effect on the rotorcraft's performance, although "one does take things easy after". In another case, although most of the blade tips were ripped off, the "symptoms in the cockpit were minimal and the helicopter landed normally". All reported leading edge damage cases were only detected after a post-flight check. One pilot commented that "leading edge damage funnily enough had little affect [sic] on flight or flying characteristics (effect)". A pilot stated that the loss of 1/3 of the blade of a mid-sized helicopter resulted in ditching.

The effect of cracks is again dependent on size: a small chordwise crack on a composite blade does not change the behaviour at all, whereas some other cracks on composite blades have a good vibration signature leading to early detection. The most difficult structural damage to detect is internal damage. Only two internal damage cases involving blades with metallic components resulted in increased and severe vibration, and in one case vertical vibration was reported due to damage on a composite blade. All other cases involving composite blades were not noticeable in flight and are often only found during a maintenance. In some cases only a slight surface discolouration was noticed after impact during chaff and flare trials, and significant debonding was discovered only through tapping tests. Small internal damage on composite blades does not necessarily mean that the blade requires immediate repair. One pilot reported that damage due to delamination was "acceptable for one more flight to repair station". With the use of a continuous health and monitoring system that allows for condition based maintenance internal damage can be monitored over time ensuring enhanced maintenance.

Damage to auxiliary components that are part of the main rotor system (such as trim tabs, pitch links or lead lag dampers) often cause increased vibration and control activity that impacts workload. For example a broken trim tab led to an aborted take-off after a marked vertical bounce (3R) was noticed during transition to forward flight at approx 40 KIAS. A heavily worn bolt fitting the blade pitch link horn and the pitch rod caused high levels of $1 \mathrm{R}$ and $4 \mathrm{R}$ vibration in translational flight. This led to a high level of stress and discomfort for pilot and crew. A lead-lag damper failure or damage also causes noticeable vibrations and/or movements in the controls. The vibration levels can be sufficiently high to cause the 
"pilot to abort a sortie with a noticeable vertical thump felt if the cyclic was moved in a circular fashion (e.g. hover spot turn through $360 \mathrm{deg}$ )". One pilot commented that during flight it is difficult, especially without specific training, to definitively diagnose what level and type of damage has occurred.

The majority of events related to environmental damage were recognised by aircrew. Water ingress often resulted in lateral vibrations. One participant mentioned that when water ingress is "very bad, it is very rough" and it can lead to stress, discomfort, distraction and such severe vibrations that the instruments could not be read. Although salt accretion resulted in the same perception and workload, no effect on handling was reported by the pilot. After flying into sleet a pilot reported that the subsequent landing was necessary due to uneven and erratic main rotor balance track. It increased power requirements and fuselage vibrations. Erosion damage was often reported to cause no effects. However, in one severe situation more torque was required to remain in the hover than predicted by the flight manual charts.

Reported maintenance related issues include mis-adjusted pitch link, mis-adjusted trim tab, or droop shroud damage. If care is not taken during maintenance significant stress related factors including distraction, fatigue and decrease in comfort can occur in flight.

The results of the survey have been arranged into different groups relating to pilot perception and workload (Fig. 3). It can be seen that most of the damage is immediately felt by the pilot either through increased vibration or noise. The relationship of how damage affects pilot workload highlights that most internal damage and all erosion type damage resulted in no additional workload even though vibration was evident.

\section{Conclusions}

This paper summarises the results of a survey carried out to obtain a view of main rotor blade damage occurring in service and their impact on today's helicopter operations. Only minor incidents were reported by the survey participants highlighting the reliability of rotor blades for the harsh operating environment, even with damage. Although this study covers feedback from subjects with a very broad range of experience, the limited number of participants has meant that it only provides a glimpse into the operational challenges faced by pilots and engineers. The survey has presented feedback that confirms widely accepted beliefs, such as the fact that visually identifiable rotor blade damage is often directly sensed by the 


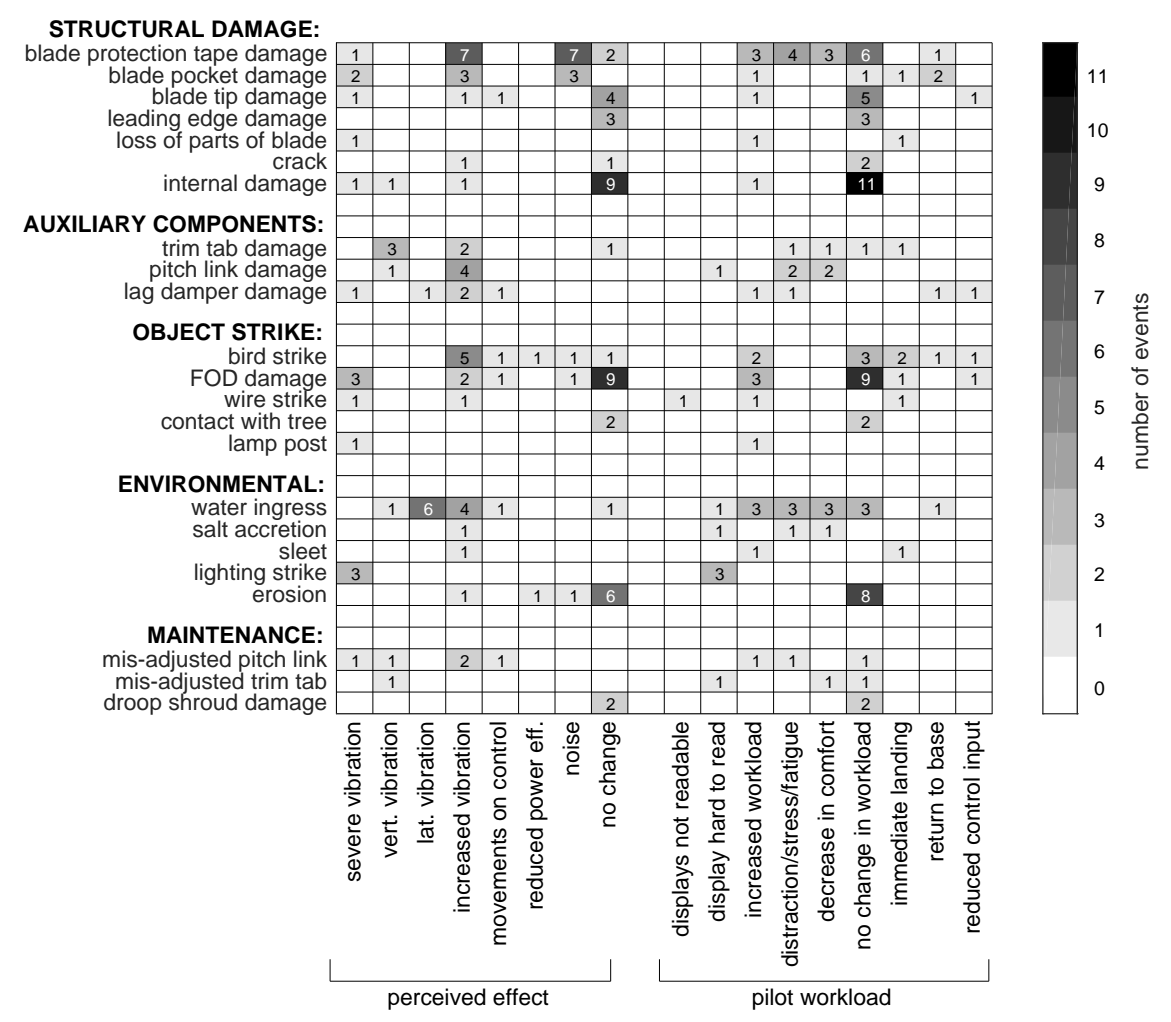

Fig. 3 Damage linked to perceived effects and pilot workload.

pilot through increased vibration or noise, while internal damage often goes unnoticed in flight and can be hard to detect, even during maintenance. However, more importantly the survey has highlighted the dichotomy faced by today's rotorcraft engineers and systems architects. There is little operational evidence that points towards the need for complex sensors on rotor blades for health monitoring due to the conservative design practices and the consequent robustness of modern composite blades. Yet, technological advancements in sensor technology are now presenting an opportunity to monitor blade dynamics in operational environments and in doing so, potentially furthering understanding of blade dynamics with/without damage and improving design methods. In short, does the designer follow today's technological trends and adopt a preventative approach where he/she invests in such instrumentation systems or is a reactive approach more appropriate where he/she awaits to have sufficient evidence of operational need?

\section{Acknowledgements}

The authors would like to thank all survey participants for their invaluable comments and feedback. The authors also also acknowledge the support of Airbus Helicopters UK, as well as ATI and Innovate 
UK. The work was carried out as part of the BladeSense project.

\section{References}

${ }^{1}$ M. Amura, L. Aiello, M. Colavita, F. De Paolis, M. Bernabei, "Failure of a helicopter main rotor blade," Procedia Materials Science, 20th European Conference on Fracture, Vol. 3, 2014, pp. 726-731.

2“"Accident $\quad$ report," https://www.ntsb.gov/investigations/AccidentReports/_layouts/ ntsb.aviation/brief.aspx?ev_id=20001213X29709\&key=1, Accessed: 11 April 2018.

${ }^{3}$ D.R. Hinson, "Safety recommendation.” Tech. Rep. A-94-189, National transportation safety board., Washington D.C., USA, 1994.

${ }^{4}$ R. Kieselbach, G. Soyka, "Failure of a helicopter rotor," Technology, Law \& Insurance, Vol. 5, No. 3/4, 2000, pp. 141-146.

${ }^{5}$ Romeyn, A., "Engineered system failure analysis report. Main rotor blade fracture Robinson R22, VH-OHA occurence 200302820," https://www.atsb.gov.au/media/25106/aair200302820_002.pdf, 2005, Accessed on 11 April 2018.

6“Aviation Investigation Report. In-flight separation of main rotor blade and collision with terrain," Tech. Rep. A1100205, Transportation Safety Board of Canada, Ontario, Canada, 2011.

7"Report on the accident to Sikorsky S-76A + , G-BJVX near the Leman 49 / 26 Foxtrot platform in the North Sea, 16 July 2002." Air Accidents Investigation Branch.

${ }^{8}$ N.J. Lourenço, M.L.A. Graça, L.A.L. Franco, O.M.M. Silva, "Fatigue failure in a military helicopter main rotor blade," http://www.metallum.com.br/20cbecimat/resumos/trabalhos_completos/315-015.doc, 2012, Accessed on 11 April 2018.

${ }^{9}$ M. Martinez, M. Yanishevsky, B. Rocha, R.M. Groves, N. Bellinger, Maintenance and monitoring of composite helicopter structures and materials, Elsevier Ltd., 2015.

${ }^{10}$ P.M. Pawar, R. Ganguli, "Helicopter rotor health monitoring - a review," Proceedings of the Institution of Mechanical Engineers, Part G: Journal of Aerospace Engineering, Vol. 221, No. 5, 2007, pp. $631-647$.

${ }^{11}$ Giurgiutiu, V., "Structural health monitoring (SHM) of aerospace composites," Polymer Composites in the Aerospace Industry, Elsevier, 2014, pp. 449-507. 
${ }^{12}$ Lombardo, D., "Helicopter structures - a review of loads, fatigue, design techniques and usage monitoring,” Tech. Rep. ARL-TR-15, Department of Defence: Defence Science and Technology Organisation, Melbourne, Australia, 1993.

${ }^{13}$ T. Kissinger, E. Chehura, S.E. Staines, S.W James, R.P. Tatam, “Dynamic fiber-optic shape sensing using fiber segment interferometry," Journal of Lightwave Technology, Vol. 36, No. 4, 2018, pp. 917-925. 14“'Special Study. Review of rotorcraft accidents 1977-1979,” Tech. Rep. NTSB-AAS-81-1, National Transportation Safety Board, Washington D.C., USA, 1981.

15“U.S. helicopter accidents decrease,” https://www.faa.gov/news/updates/?newsId =87406, Accessed: 10 April 2018.

16“EASA Certification Specification. CS-29: Easy access rules for large rotorcraft (amendment 4)," 2018

${ }^{17}$ J.S. Harris, "Analysis of Sikorsky S-76 helicopter data shows comparatively low accident rate," Flight Safety Foundation: Helicopter Safety, Vol. 20, No. 1, 1994, pp. 1-6.

18“Helicopter Accidents: Statistics, Trends and Causes [PowerPoint presentation]. IHST Regional Partners Panel," http://www.ihst.org/portals/54/symposium/2016/Presentation\%20IHST-CIS_2016.pdf, 2016, Accessed on 10 April 2018.

19“Some significant wildlife strikes to civil aircraft," Tech. rep., FAA Wildlife Strike Database, Sandusky, USA, 2010.

${ }^{20}$ V.T. Nagaraj, I. Chopra, "Safety study of wire strike devices installed on civil and military helicopters," Tech. Rep. DOT/FAA/AR-08/25, Air Traffic Organization Operations Planning Office of Aviation Reserach and Development, Washington D.C., USA, 2008.

${ }^{21}$ I.A. Herrera, S. Habrekke, T. Krakenes, P.R. Hokstad, U. Forseth, “Helicopter Safety Study 3,” Tech. Rep. SINTEF A15753, SINTEF Technology and Society, Trondheim, Norway, 2010.

22“"Sikorsky Helicopters,” Flight International, Vol. 10 October, 1963, pp. 614-615. 


\section{List of Figures}

1 Respondents flying experience. . . . . . . . . . . . . . . . . . 4

2 Awareness of damage during flight for all occurrences. . . . . . . . . . . . . . . 6

3 Damage linked to perceived effects and pilot workload. . . . . . . . . . . . . . 9 
2019-08-01

\title{
Technical note: recent experiences of helicopter main rotor blade damage
}

\author{
Weber, Simone
}

Vertical Flight Society

Weber S, Lone M, Cooke A. (2019) Recent experiences of helicopter main rotor blade damage.

Journal of the American Helicopter Society, Volume 64, Issue 3, July 2019, Article number 035001 https://doi.org/10.4050/JAHS.64.035001

Downloaded from Cranfield Library Services E-Repository 